\title{
Modeling and Simulation of Power Coupling System in Hydraulic Hybrid City Bus
}

\author{
Xunming Li, Jinyu Qu, Wei Wei, Xiangyu Tian \\ School of Transport and Vehicle Engineering, Shandong University of Technology, Zibo, China \\ Email: qujinyu@sdut.edu.cn
}

Received 23 April 2014; revised 23 May 2014; accepted 28 May 2014

Copyright (C) 2014 by authors and Scientific Research Publishing Inc.

This work is licensed under the Creative Commons Attribution International License (CC BY).

http://creativecommons.org/licenses/by/4.0/

(c) (i) Open Access

\begin{abstract}
In order to solve the coupling problem of power in Hydraulic Hybrid City Bus (HHB), a hydraulic hybrid power coupling system based on planetary gear transmission principle is proposed in this paper. The system consists of diesel engine, power coupler, hydraulic pump/motor, etc. The realizable operating modes of power coupling system are analyzed in this paper. Under coordination of clutches, the engine driven mode, hydraulic driven mode, hybrid driven mode, hydraulic enginestart mode and braking energy recovery mode are realizable. Based on Lagrange equation, kinetic analysis and kinematics analyses are presented. In addition, the simulation model of the power coupling system is proposed, which includes diesel engine model, power coupler model, hydraulic pump/motor model, etc. The example simulation analysis is proposed under the hybrid driven mode; the results show that the power coupling system proposed in this paper can realize power coupling of hydraulic hybrid city bus. Compared with traditional city bus, the hydraulic hybrid city bus can choose small-displacement engine so as to improve fuel economy and dynamic property.
\end{abstract}

\section{Keywords}

HHB; Power Coupling System, Planetary Gear Trans, Hydraulic Starting

\section{Introduction}

The hydraulic hybrid utilizes a high pressure accumulator for energy storage which has more superior power density than conventional battery technology. This makes fluid power attractive for urban driving applications in which there are frequent starts and stops and large startup power demands [1]. The hydraulic hybrid city bus has great application value, and this is an effective way for energy conservation and emission reduction. The power coupling is the key technology of the hydraulic hybrid city bus and the planetary gear transmission mechanism is used most frequently. 
Many scholars have researched the power coupling problem of the hydraulic hybrid bus, and some achievements were achieved. Wojnarowski, Sherman and Wojnarowski J. proposed the bond graph model of epicyclical gear transmission and planetary gear transmission. The methodology of gear system kinetic analysis and kinematics analysis are developed based on graph theory [2]-[4]. Guoqi He and L. W. Tsai proposed power coupling system of hybrid bus based on planetary gear transmission, and the lever analogy was used to analyze the speed characteristic and torque characteristic of power coupling system [5] [6]. The results show that many operating modes of hybrid bus can be realized by planetary gear transmission system.

A power coupling system of hydraulic hybrid bus is proposed in this paper, based on epicyclical gear transmission. Many operating modes of hydraulic hybrid city bus were realized by cooperation of many clutches. The power coupling system was used on the Yu Tong ZK6126HG city bus, and the coupling property under hybrid driven mode was analyzed. Diesel engine model, hydraulic accumulator model and hydraulic pump/motor model were established; in addition, the mathematic model of coupler based on Lagrange equation was established. All the models were simulated under Matlab/Simulink simulation environment. The results show that the power coupling system can solve the power coupling problem of the hydraulic hybrid bus effectively, and the vehicle dynamic property improved obviously under the same fuel consumption.

\section{Design of Power Coupling System}

This paper studies a power coupling system applied to hydraulic hybrid city bus. Figure 1 shows the schematic diagram of power coupling system. The power coupling system is made up of engine and epicyclical gear transmission integrated with a hydraulic motor that can also function as a hydraulic pump. In the figure, the power coupler is set between engine crankshaft and engine flywheel. The engine crankshaft is connected to the sun gear of power coupler, and the sun gear can be integrated or separated with planet carrier by clutch $\mathrm{C} 1$. The output shaft of hydraulic motor is connected to the gear ring of power coupler by clutch C2. The output shaft of power coupler or the output shaft of planet carrier of power coupler is connected to the transmission of the vehicle. In follows, the component models are built and the characteristic of the power coupling system is analyzed.

\section{Operating Modes of Power Coupling System}

The hydraulic hybrid city bus drives on certain mode based on different driving cycle, and realizes energy conservation and emission reduction with braking energy regeneration.

\subsection{Engine Driven Mode}

To launch the vehicle from a standstill and for driving in city traffic, the clutch C1 is engaged and the clutch C2 is disengaged. At this time, the sun gear integrated with planet carrier, and the transmission ratio between engine and transmission is one. The engine is used to drive the city bus, individually, and the dynamic property of the city bus is not influenced compared with the traditional city bus. The power transmission line is shown in Figure 2. In the follow figures of this paper, the clutch of black color indicates that the clutch is engaged and the clutch of white color indicates that the clutch is disengaged.

\subsection{Hydraulic Driven Mode}

Hydraulic accumulator has the advantage of higher power density and the ability to accept the high rates and high frequencies of charging and discharging, both of which are not favorable for batteries [7]. As a result, the hydraulic hybrid city bus stores the braking energy in the hydraulic accumulator as a form of hydraulic energy. When the hydraulic hybrid city bus works on the starting or climbing conditions, the hydraulic energy is translated to the kinetic energy of the bus to reach the purpose of energy conservation and emission reduction. Figure 3 shows the power transmission line of hydraulic driven mode.

Under hydraulic driven mode, both clutch C1 and clutch C2 are engaged, the energy of hydraulic accumulator is translated into mechanical energy of hydraulic motor, and the hydraulic hybrid city bus is droved by the hydraulic motor. At the same time, the engine crankshaft also be droved, the engine is started at the end of releasing of hydraulic accumulator energy. The clutch C2 is disengaged after the engine is started, and the working mode turns into the engine driven mode as mentioned above. The hydraulic driven mode adopts the low speed 


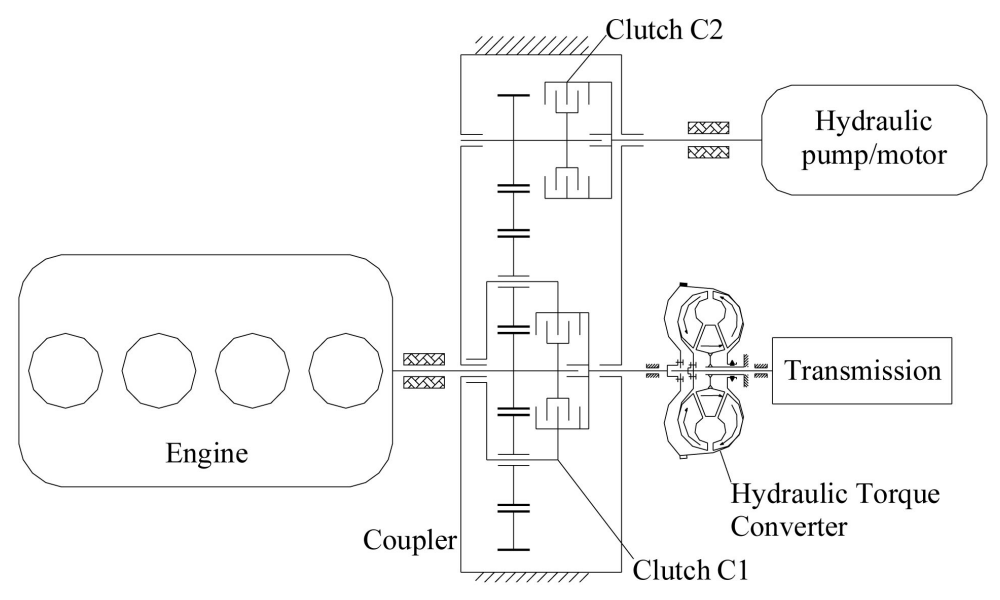

Figure 1. The schematic diagram of power coupling system.

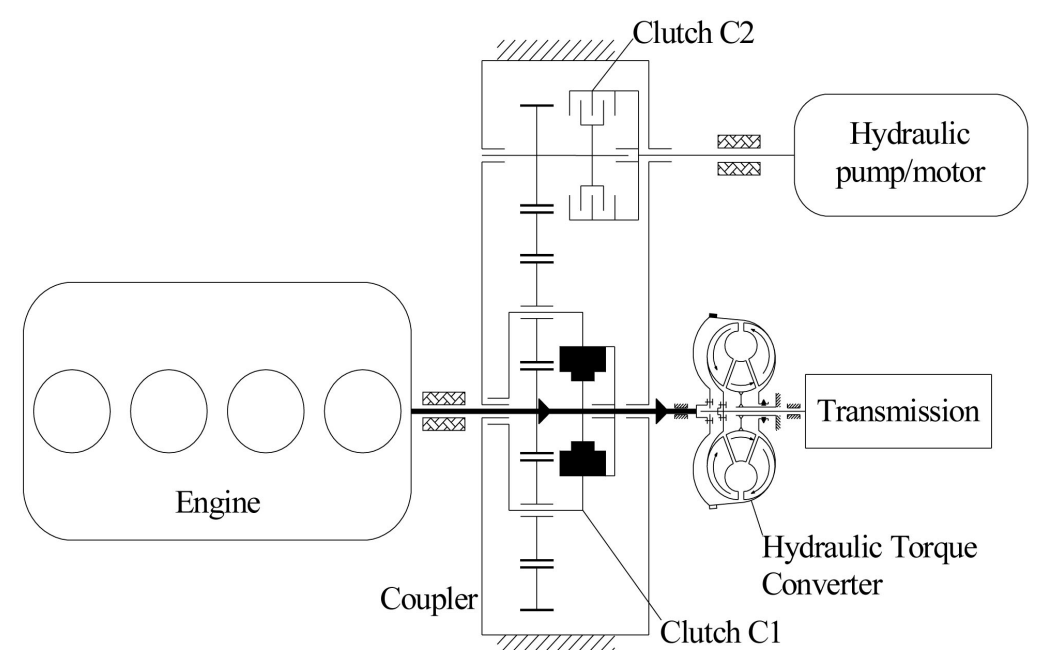

Figure 2. Power transmission line of engine driven mode.

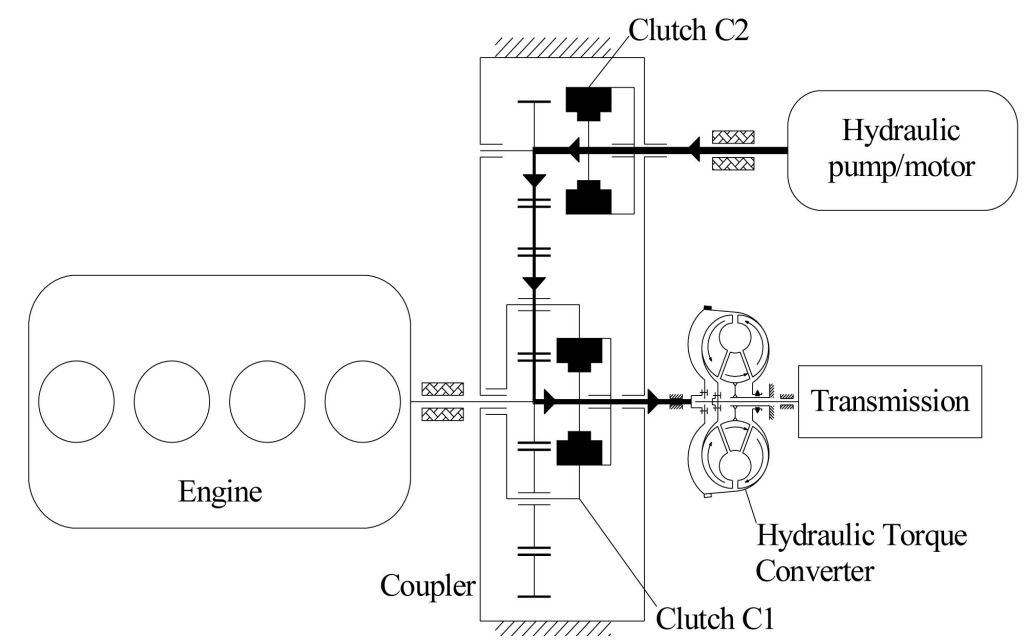

Figure 3. Power transmission line of hydraulic driven mode.

high torque characteristic of hydraulic motor, and the engine working conditions of light load, low efficiency and high emissions are avoided [8]. In addition, the purpose of the engine always working on the economy re- 
gion is reached.

\subsection{Hybrid Driven Mode}

Simpson planet gear mechanism belongs to $2 \mathrm{~K}-\mathrm{H}$ type epicyclical gear transmission, which has two degree of freedom when all elements are flexible [9]. Two input torques can be synthesized to one output torque at advantage of this feature. If the hydraulic hybrid city bus running in hybrid driven mode, clutch C2 should be engaged while clutch C1 should be disengaged. The power transmission line of hybrid driven mode is shown in Figure 4. The engine power and the hydraulic motor power synthesized in the power coupler, and then output to transmission to drive the city bus. Hydraulic energy storage system features high frequency response, high power density, simple system structure, compatible technology and remarkable energy-saving and emissions reduction effect [10]-[13]. Under the working condition of starting or climbing, some auxiliary power can be added to the hydraulic hybrid city bus to improve the dynamic property, and ensure that the engine works in the economy region, which is helpful to reduce fuel consumption and emission.

\subsection{Hybrid Driven Mode}

Two engine hydraulic start modes are proposed by the power coupling system: standstill hydraulic start and dynamic hydraulic start. The standstill hydraulic start is that the bus hydraulically starts when the hydraulic accumulator pressure is low. The hydraulic energy is released from the hydraulic accumulator and translated to mechanical energy by hydraulic motor, and then drive the engine to idling speed. The dynamic hydraulic start works when the hydraulic accumulator pressure is high. At this time, both clutch C1 and C2 should be engaged, and the transmission is in a non-neutral state. The city bus and engine are droved by hydraulic motor in the meantime. Clutch C2 is disengaged, and the engine is started by the inertia of the city bus, when the end of the hydraulic energy release. The power transmission line of engine hydraulic start mode is shown in Figure 5.

The engine hydraulic start mode reduces fuel consumption and emission during the engine start, and then the engine works in an economy region. Compared with the traditional way of engine start, higher torque can be output, and engine cannot be influenced by temperature at the engine hydraulic start mode.

\subsection{Braking Energy Recovery Mode}

Hydraulic braking force and mechanical friction braking force can be distributed reasonably, depending on the demand of braking intensity of power coupling system.

Under the condition of low braking intensity, clutch C2 is engaged and clutch C1 is disengaged. The hydraulic braking works alone, all of the braking energy is recovered into the hydraulic accumulator.

Under the condition of middle braking intensity, clutch C2 is engaged and clutch C1 is disengaged. The hydraulic braking and the mechanical braking combine to work, and most of the kinetic energy is recovered into the hydraulic accumulator. This mode can not only recycle the braking energy but also reduce the braking intensity, which prolongs the life of the braking. Figure 6 shows the power transmission line of braking energy recovery mode under low and middle braking intensity.

Under the condition of high braking intensity, both clutch C1 and clutch C2 are engaged. Hydraulic pump, engine and mechanical braking work to decelerate the city bus. The power transmission line of braking energy recovery mode under high braking intensity is shown in Figure 7. When the bus is driving on slippery roads or steep roads, the braking energy recovery mode can avoid using the mechanical braking frequently [14]. Obviously, this mode is helpful to prolong the life of braking discs, slow down heat fade and water fade, and improve the braking efficiency and safety of the city bus.

\section{Characteristic Analysis of Power Coupling System}

\subsection{Kinematics Analysis of Power Coupling System}

1) Speed calculation of planet carrier of the power coupler

The conversion of the epicyclical gear train is the ordinary fixed axis gear train, and the method solving transmission ratio of fixed axis gear train can be used to calculate transmission ratio of epicyclical gear train [15]. According to the transmission ratio equation of the epicyclical gear train, the transmission ratio of the gear 


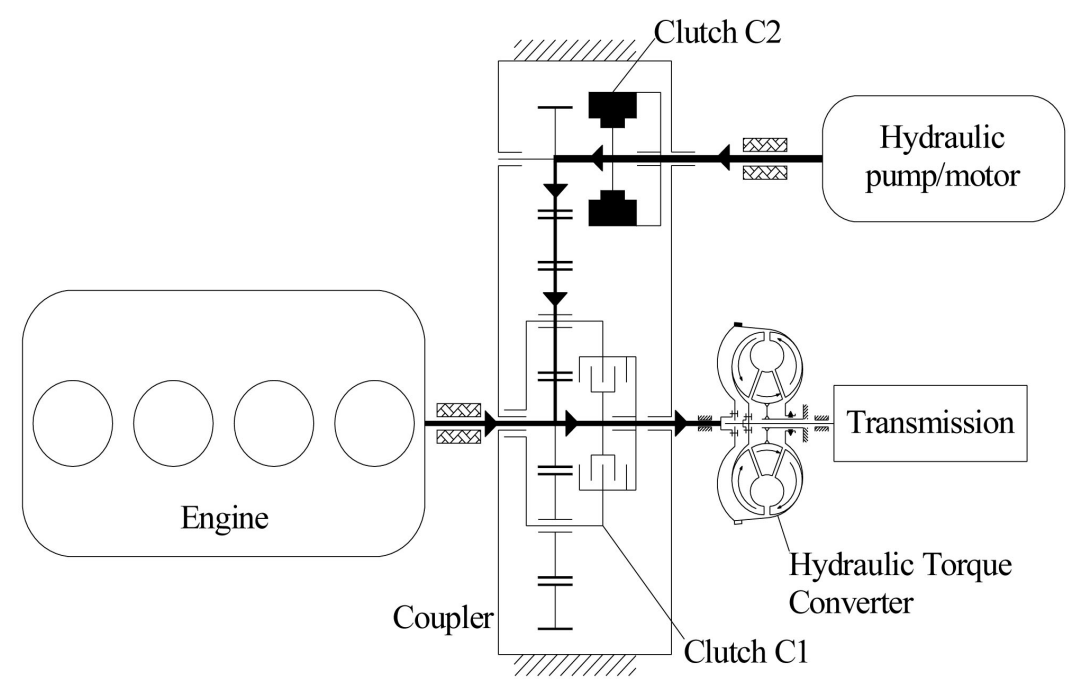

Figure 4. Power transmission line of hybrid driven mode.

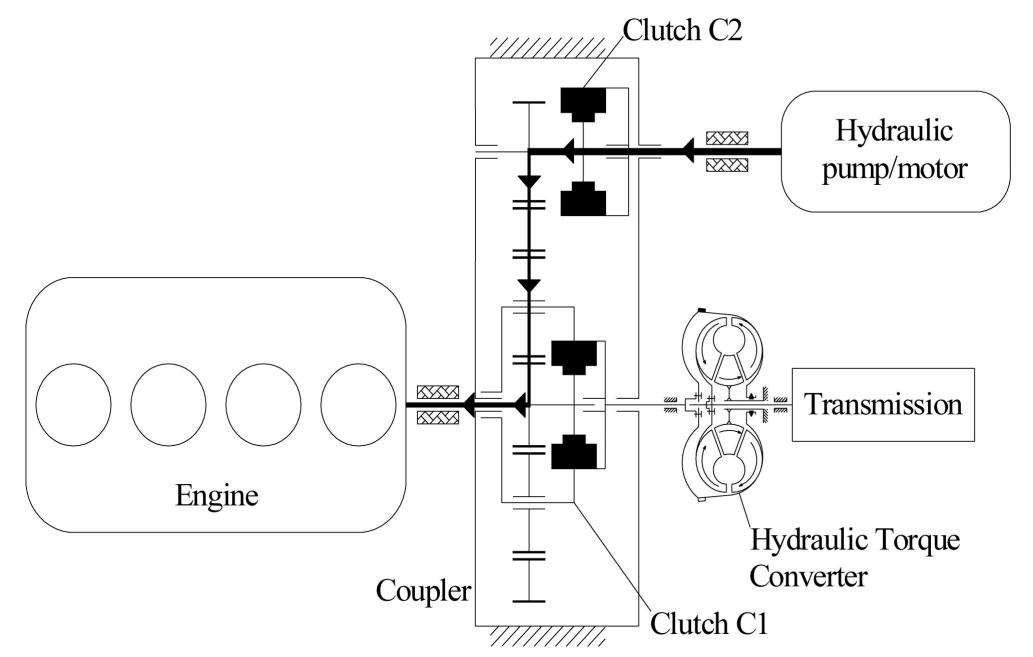

Figure 5. Power transmission line of engine hydraulic start mode.

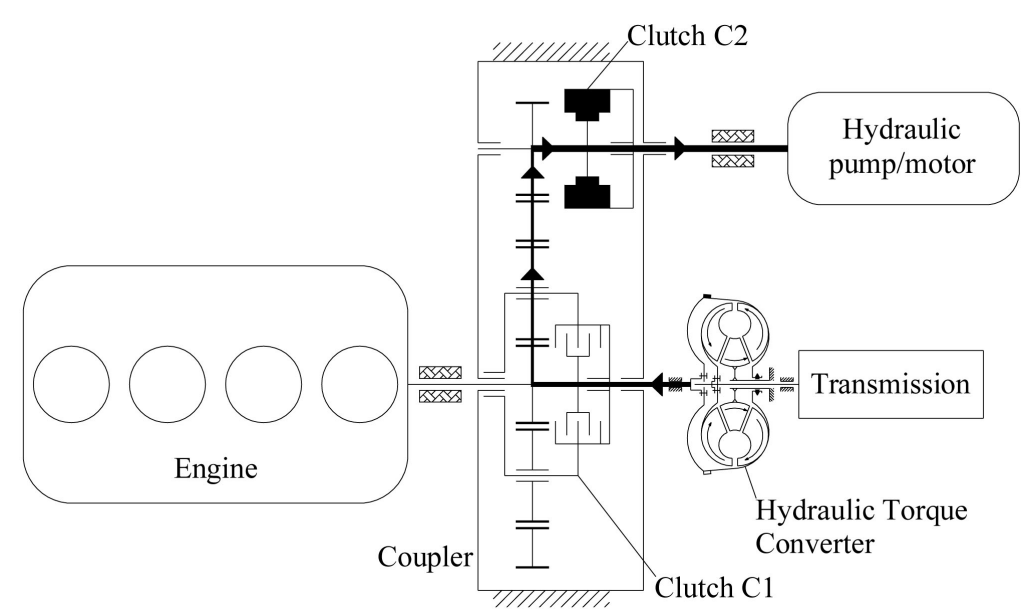

Figure 6. Power transmission line of braking energy recovery mode under low and middle braking intensity. 


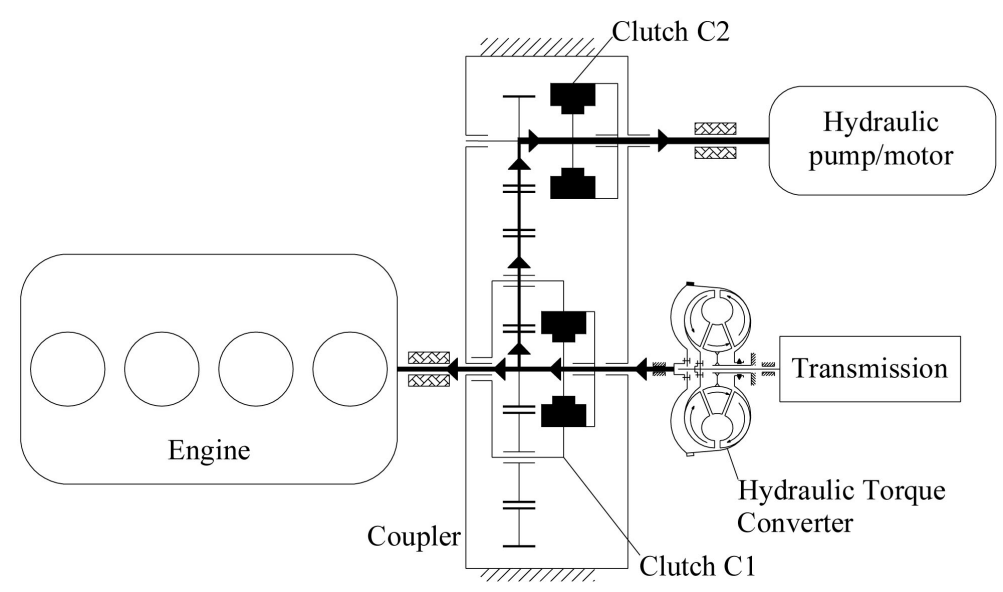

Figure 7. Power transmission line of braking energy recovery mode under high braking intensity.

ring and the sun gear is shown as Equation (1).

$$
\frac{n_{s}^{H}}{n_{r}^{H}}=\frac{n_{s}-n_{H}}{n_{r}-n_{H}}=-\beta
$$

where $\beta$ is the transmission ratio between sun gear and ring gear, relative to the planet carrier; $n_{s}^{H}$ is the speed of sun gear, relative to the planet carrier; $n_{r}^{H}$ is the speed of gear ring, relative to the planet carrier; $n_{r}$ is the actual speed of gear ring; $n_{s}$ is the actual speed of sun gear; and $n_{H}$ is the actual speed of planet carrier.

From Equation (1), we have

$$
\omega_{s} R_{s}+\beta \omega_{r} R_{r}-(1+\beta) \omega_{H} R_{H}=0
$$

where $\omega_{s}$ is the angular speed of sun gear; $\omega_{r}$ is the angular speed of gear ring; $\omega_{H}$ is the angular speed of planet carrier; $R_{H}$ is the radius of planet carrier; $R_{S}$ is the radius of sun gear; and $R_{r}$ is the radius of gear ring.

From Equation (2), we have the angular speed of planet carrier of the power coupler:

$$
\omega_{H}=\frac{R_{s}}{(1+\beta) R_{H}} \omega_{s}+\frac{\beta R_{r}}{(1+\beta) R_{H}} \omega_{r}
$$

2) Speed calculation of planet gear of the power coupler

As shown in Figure 8, assume the gear ring of the power coupler holds still, calculate and analyze the relation between the sun gear and the planet gear.

The motion of any point in the plane graphics can be regard as synthesis of the two movements, and the speed of any point can be calculated depend on speed synthesis theorem [16]. Angular speed is a vector and the definition of plus and minus are described below: from the positive end of the shaft, if the rigid body is turning counterclockwise, the angular speed takes the positive value, otherwise, the negative value. Assume $A$ as the basic point, the speed relation between the sun gear and the planet gear is:

$$
u_{C}=u_{A}+u_{C A}
$$

where $\mu_{C}$ and $\mu_{A}$ is the linear speed of point $C$ and $A$, respectively; $\mu_{C A}$ is the speed of point $C$ relative to point $A$.

From Equation (4), we have the angular speed relation of sun gear, planet carrier and planet gear:

$$
\omega_{s} \cdot R_{s}=\omega_{H} \cdot R_{H}-\omega_{p} \cdot R_{p}
$$

where $\omega_{p}$ is the angular speed of planet gear; $R_{p}$ is the radius of planet gear.

As shown in Figure 9, assume the sun gear of the power coupler holds still; calculate the speed relation between the gear ring and the planet gear.

The sun gear of the power coupler holds still, takes $A$ as the basic point. The speed relation between the gear ring and the planet is: 


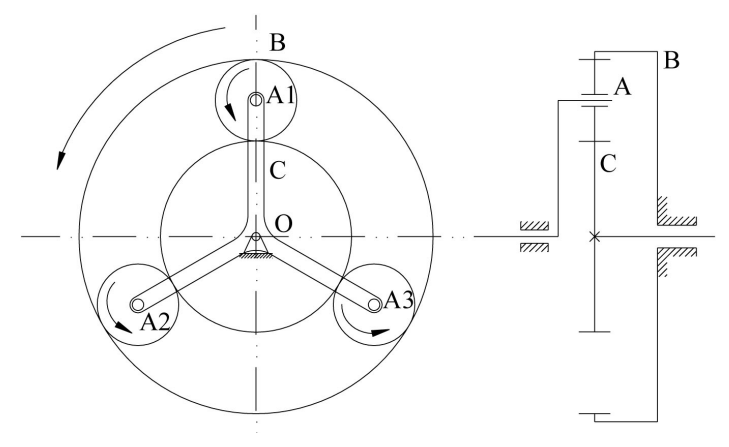

Figure 8. The schematic diagram of the sun gear driving the planet carrier.

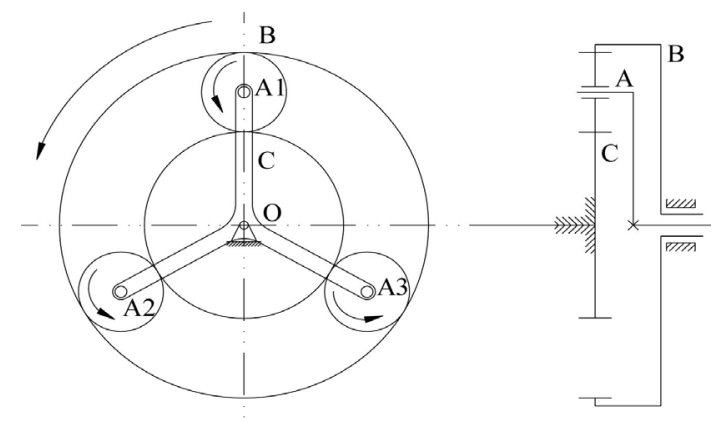

Figure 9. The schematic diagram of the gear ring driving the planet carrier.

$$
u_{B}=u_{A}+u_{B A}
$$

where $\mu_{B}$ is the linear speed of point $B$; $\mu_{B A}$ is the speed of point $B$ relative to point $A$.

From Equation (6), the angular speed relation of gear ring, planet carrier and planet gear is:

$$
\omega_{r} \cdot R_{r}=\omega_{H} \cdot R_{H}+\omega_{p} \cdot R_{p}
$$

From Equation (5) and Equation (7), the angular speed of planet gear is:

$$
\omega_{p}=\frac{R_{r}}{2 R_{p}} \omega_{r}-\frac{R_{s}}{2 R_{p}} \omega_{s}
$$

\subsection{Kinetic Analysis of Power Coupling System}

Take the angular displacement of crankshaft $\left(\theta_{s}\right)$ and the angular displacement of the hydraulic motor output shaft $\left(\theta_{r}\right)$ as the generalized coordinates. The relative angular speed is the generalized angular speed, that is $\dot{\theta}_{s}=\omega_{s}, \quad \dot{\theta}_{r}=\omega_{r}$. The kinetic energy of the power coupling system is:

$$
E=\frac{1}{2} J_{s} \dot{\theta}_{s}^{2}+\frac{1}{2} J_{H} \dot{\theta}_{H}^{2}+\frac{1}{2} J_{r} \dot{\theta}_{r}^{2}+\frac{1}{2} J_{p} \dot{\theta}_{p}^{2}+\frac{3}{2} m_{p} \cdot R_{H}^{2} \cdot \omega_{H}^{2}
$$

where $J_{s}$ is the moment of inertia of the engine output shaft and its pontes; $J_{H}$ is the moment of inertia of the transmission output shaft and its pontes; $J_{r}$ is the moment of inertia of the pump motor output shaft and its pontes; $J_{p}$ is the moment of inertia of the planet wheel of the power coupling system; $m_{p}$ is the mass of the planet gear.

From Equation (3), (8), (9), we have Equation (10):

$$
E=\frac{1}{2} J_{11} \omega_{s}^{2}+J_{12} \omega_{s} \omega_{r}+\frac{1}{2} J_{22} \omega_{r}^{2}
$$


where

$$
\begin{gathered}
J_{11}=J_{s}+J_{H}\left[\frac{R_{s}}{(1+\beta) R_{H}}\right]^{2}+J_{p}\left(\frac{R_{s}}{2 R_{p}}\right)^{2}+3 m_{p} R_{H}^{2}\left[\frac{R_{s}}{(1+\beta) R_{H}}\right]^{2} \\
J_{12}=J_{H} \frac{\beta R_{s} R_{r}}{\left[(1+\beta) R_{H}\right]^{2}}-J_{p} \frac{R_{s} R_{r}}{\left(2 R_{p}\right)^{2}}+3 m_{p} R_{H}^{2} \frac{\beta R_{s} R_{r}}{\left[(1+\beta) R_{H}\right]^{2}} \\
J_{22}=J_{r}+J_{H}\left[\frac{\beta R_{r}}{(1+\beta) R_{H}}\right]^{2}+J_{p}\left(\frac{R_{r}}{2 R_{p}}\right)^{2}+3 m_{p} R_{H}^{2}\left[\frac{\beta R_{r}}{(1+\beta) R_{H}}\right]^{2}
\end{gathered}
$$

The generalized force corresponded to $\theta_{s}$ and $\theta_{r}$ is torque, the power of all external force is:

$$
P=T_{s} \cdot \omega_{s}+T_{H} \cdot \omega_{H}+T_{r} \cdot \omega_{r}
$$

where $T_{s}$ is the output torque of engine; $T_{r}$ is the output torque of hydraulic motor; $T_{H}$ is the input torque of transmission.

From Equation (3) and Equation (14), the power of external force is:

$$
P=\left(T_{s}+\frac{R_{s} \cdot T_{H}}{(1+\beta) R_{H}}\right) \cdot \omega_{s}+\left(T_{r}+\frac{\beta R_{r} T_{H}}{(1+\beta) R_{H}}\right) \cdot \omega_{r}
$$

The generalized force corresponded to $\theta_{s}$ and $\theta_{r}$ is:

$$
\begin{gathered}
Q_{r}=T_{r}+\frac{\beta R_{r}}{(1+\beta) R_{H}} T_{H} \\
Q_{s}=T_{s}+\frac{R_{s}}{(1+\beta) R_{H}} T_{H}
\end{gathered}
$$

\section{Mathematical Model of Power Coupling System}

\subsection{Model of the Power Coupler}

The Lagrange equation [17], named after Joseph Louis Lagrange, is an important equation of Lagrange mechanics. The Lagrange equation can be used to describe the movement of object. Put the generalized force into the Lagrange equation, we have:

$$
\left[\begin{array}{ll}
J_{11} & J_{12} \\
J_{12} & J_{22}
\end{array}\right]\left[\begin{array}{l}
\ddot{\theta}_{s} \\
\ddot{\theta}_{r}
\end{array}\right]=\left[\begin{array}{l}
Q_{s} \\
Q_{r}
\end{array}\right]
$$

Aliased as

$$
\boldsymbol{J} \boldsymbol{\alpha}=\boldsymbol{T}
$$

where $\boldsymbol{J}$ is the moment of inertia of the components of the planet gear; $\boldsymbol{\alpha}$ is the acceleration matrix of the sun gear and the gear ring; $\boldsymbol{T}$ is the generalized force matrix.

Equation (19) is the model of the power coupler, solve Equation (19), we have the relation of the engine torque, the hydraulic motor torque and the output torque of the power coupler.

From Equation (5) and (7), the coupling model of the power coupler is:

$$
2 \omega_{H} R_{H}=\omega_{s} R_{s}+\omega_{r} R_{r}
$$

\subsection{Diesel Engine Model}

In this work, the engine simulation model is simplified to accommodate the need of top-level control strategy design. A lookup table of engine brake torque versus engine speed is directly derived from the engine brake specific fuel consumption map (Figure 10), which was generated from experimental data obtained in the Hybrid 


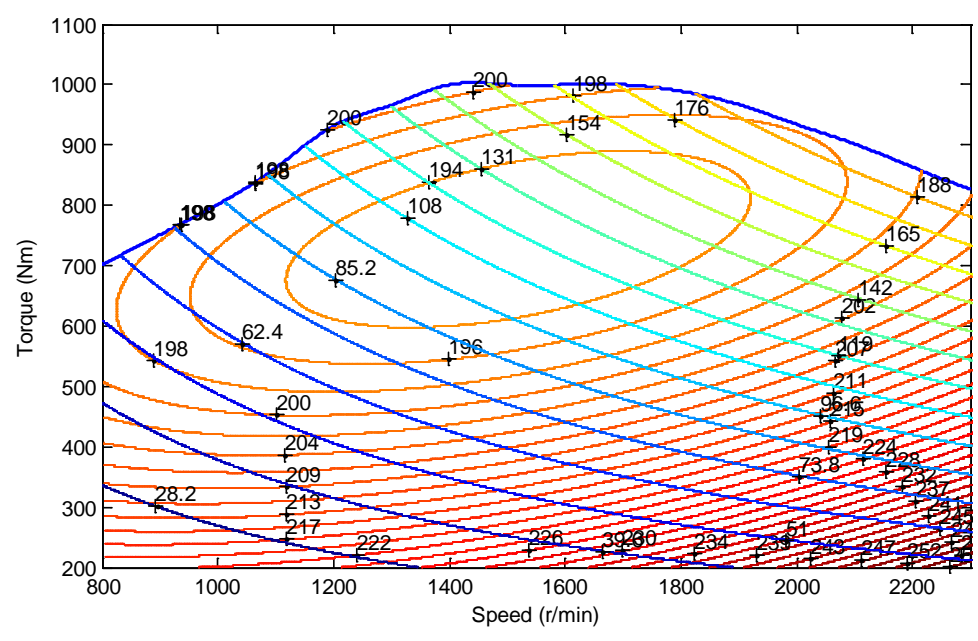

Figure 10. Engine universal characteristics curve.

and Power Trains Laboratory at the Shandong University of Technology.

The instantaneous engine torque is approximately decided by the following equation:

$$
T_{e}(w)=\mu T_{\text {emax }}(w)
$$

Here, $u$ is a nominal control signal adjusting the engine throttle position and therefore determines the engine torque output. The values of $u$ are in the domain [0,1], with 0 and 1 indicating closed throttle and wide-openthrottle position, respectively. $T_{e \max }(w)$ is the maximum available engine brake torque which is the function of the engine speed and described by the lookup table of wide-open-throttle engine brake toque.

\subsection{Hydraulic Pump/Motor Model}

When the bladder accumulator in application, the medium (nitrogen gas) can be regarded as a single thermodynamic system and the working process of bladder accumulator is regarded as the process that the single thermodynamic system translates energy with surrounding [18]. From Boyle’s gas law, we have

$$
T_{\text {emax }}(w) p_{0} V_{0}^{n}=p_{1} V_{1}^{n}=p_{2} V_{2}^{n}=\text { const }
$$

where $V_{0}, V_{1}$, and $V_{2}$ is the gas volumes under the pressure $p_{0}, p_{1}$ and $p_{2}$, respectively; $n$ is the polytrophic exponent, and $n$ takes one at the process of isothermal change or takes one point four at the process of adiabatic change.

The relation of the accumulator pressure and the hydraulic pump/motor torque is:

$$
M=\frac{V_{g} \cdot \Delta p \cdot \eta_{m}^{\operatorname{sgn}\left(T_{e}\right)}}{2 \pi}
$$

where $V_{g}$ is the accumulator displacement; $\Delta p$ is the pressure variation of the accumulator; $\eta_{m}$ is the mechanical efficiency of the hydraulic system.

\subsection{Hydraulic Accumulator Model}

The hydraulic accumulator is an important component of storing energy as a secondary power source for parallel hydraulic hybrid vehicle. In this way, accumulator is similar, in function, to the counterpart of electric batteries in the electric hybrid vehicles. Figure 11 shows the thermodynamics process of a hydraulic accumulator charge and regenerate braking energy. Where, $p$ and $V$ is the gas pressure and specific volume, respectively.

The process 1 to 2 shows that hydraulic accumulator release gas energy and increase volume, the process 3 to 4 shows that hydraulic accumulator store gas energy and decrease volume. Both the process 1 to 2 and the process 3 to 4 are finished instantaneously and for modern bladder accumulators, the higher cycle rates and the application of elastomeric foams on the inner bladder wall lead to little or no heat transferred into or out of the 


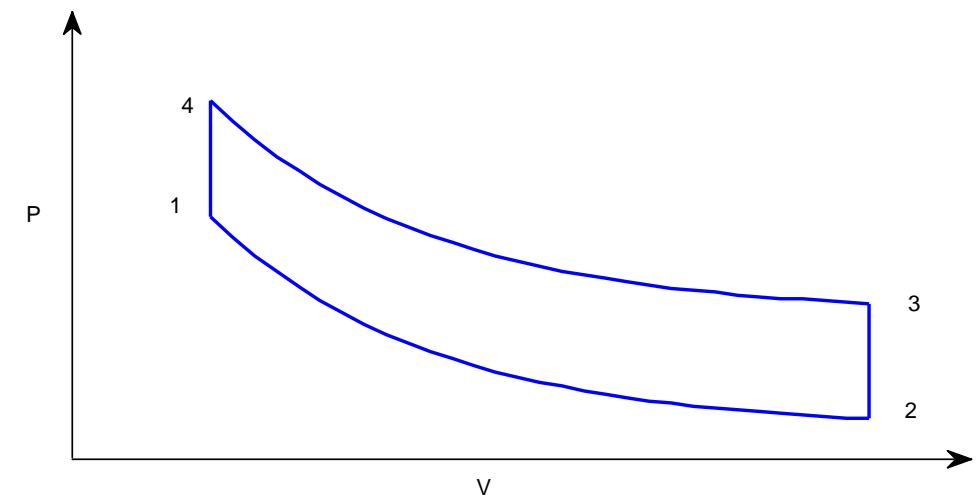

Figure 11. The working cycle of the hydraulic accumulator thermodynamics process.

accumulators, so we should assume that the compression and expansion of gas is adiabatic. The process 2 to 3 and the process 4 to 1 are the isometric process. Gas temperature returns to ambient temperature. The dynamic accumulator model is based on the following equation:

$$
p V^{n}=C
$$

Here, $p$ is supply pressure; $V$ is gas volume; $n$ is polytrophic index within a range between 1 (isothermal process) and 1.4 (adiabatic process); $C$ is constant and depends on pre-charge pressure.

Derivative the Equation (24) on both sides, we get:

$$
\frac{\mathrm{d} V}{\mathrm{~d} t}=-\frac{V^{n}}{n p V^{n-1}} \cdot \frac{\mathrm{d} p}{\mathrm{~d} t}
$$

From the Equation (25) and Equation (26) we get:

$$
\frac{\mathrm{d} V}{\mathrm{~d} t}=-\frac{C^{1 / n}}{n} \cdot \frac{1}{p^{1+1 / n}} \cdot \frac{\mathrm{d} p}{\mathrm{~d} t}
$$

where, the minus indicates that when the pressure of hydraulic accumulator increases, the gas volume in the inner bladder of the hydraulic accumulator decreases.

For a hydraulic accumulator, if we ignore the change of the quality and the volume of the hydraulic oil, the fluid volume that into and out of hydraulic accumulator equal to the change rate of the gas volume of bladder in the hydraulic accumulator. We get:

$$
Q_{a}=\frac{\mathrm{d} V}{\mathrm{~d} t}
$$

\section{Simulation and Analysis of the Results}

The simulation model can be established according to the mathematical model of the power coupling system under Matlab/Simulink. Copy relative functional modules to the simulation environment; connect each block diagram according to the flow direction of the signal, create a signal source, and then assign simulation results to relative variables, and finally draw curves in workspace.

In the simulation model, the input torque of the power coupler is the engine output torque under China typical city bus driving cycle. To keep the high efficiency, the solver is the key. Variable step size 4 order 5 order Runge-Kutta algorithm (ode 45) is employed according to the simulation model of the coupler. The parameters of the test vehicle are shown in Table 1.

Figure 12 shows China typical city bus driving cycle, which is established depending on Recommended Practice for Measuring Fuel Economy and Emissions of Hybrid-Electric and Conventional Heavy Duty Vehicles (SAEJ2711). The pressure change of hydraulic accumulator under China typical city bus driving cycle, and the hydraulic motor output torque while the releasing its energy under China typical city bus driving cycle are also 
Table 1. Parameters of the test hydraulic hybrid city bus.

\begin{tabular}{|c|c|c|c|c|c|}
\hline \multirow{3}{*}{$\begin{array}{c}\text { Engine } \\
\text { parameters }\end{array}$} & Rated speed $/ \mathrm{r} \cdot \min ^{-1}$ & 2300 & \multirow{3}{*}{$\begin{array}{c}\text { Hydraulic pump/motor } \\
\text { parameters }\end{array}$} & Flow $/ \mathrm{L} \cdot \min ^{-1}$ & 266 \\
\hline & Rated power $/ \mathrm{kW}$ & 185 & & Displacement/ml & 160 \\
\hline & Maximum torque/Nm & 1000 & & Maximum torque/Nm & 889 \\
\hline \multirow{3}{*}{$\begin{array}{c}\text { Vehicle } \\
\text { parameters }\end{array}$} & Loaded quality/kg & 165,00 & \multirow{3}{*}{$\begin{array}{c}\text { Hydraulic accumulator } \\
\text { parameters }\end{array}$} & Capacity/L & 96 \\
\hline & Frontal area $/ \mathrm{m}^{2}$ & 6 & & Rated pressure/MPa & 16 \\
\hline & Tire radius/m & 0.51 & & Maximum pressure/MPa & 31.5 \\
\hline
\end{tabular}

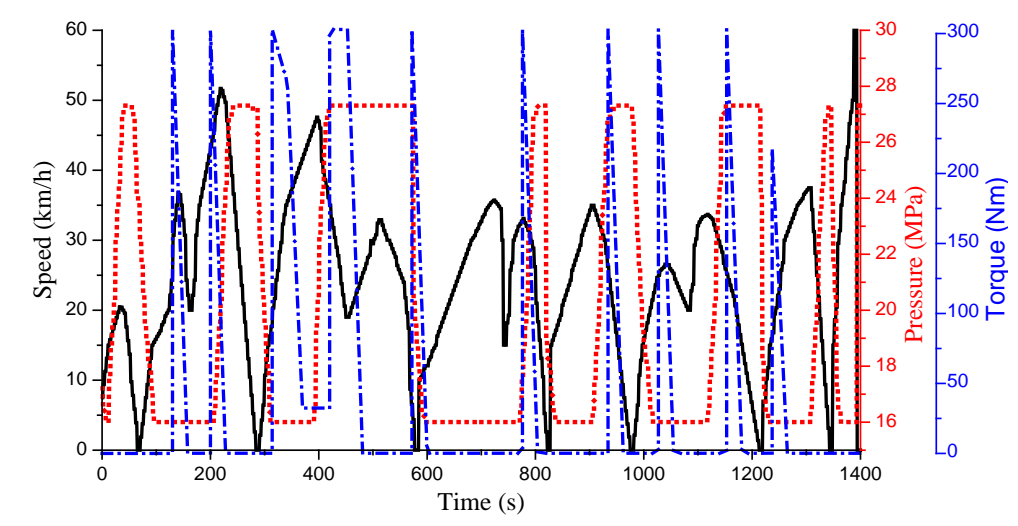

Figure 12. Driving cycle curve, accumulator pressure curve, and accumulator pressure curve.

should in the Figure 12. From the curves, we know that hydraulic accumulator and hydraulic motor can supply high instantaneous torque, which can be used to improve the dynamic property while the hydraulic hybrid city bus under the conditions of acceleration and climbing.

Figure 13 shows the desired torque. The torque coupling property, speed coupling property and power coupling property of the power coupling system is shown in Figure 14, Figure 15 and Figure 16, respectively. As shown in the curves, the power coupling system, proposed in this paper, can solve the coupled problem of the hydraulic hybrid city bus effectively. The low-powered engine can be taken while the hydraulic motor is the auxiliary power, then the engine work in the economic fuel consumption region to improve the fuel economy and emission performance.

From these figures, one can see that the power coupling system played an important role when the vehicle in the climbing condition. At this time, stored accumulator energy is used to supply much of the power demand, with the engine being used to supply short bursts of power. For the certain power demand, the large displacement engine can be replaced by a little one, and the remaining power added by the hydraulic motor. Therefore, the purpose of energy conservation and emission reduction can be achieved.

Furthermore, the power of hydraulic motor is supplied by the hydraulic accumulator, when the accumulator at the low energy, all power should be present by engine, and there will be high fuel consumption. To solve this problem, a cooperation strategy between engine and hydraulic motor should be designed.

\section{Conclusions}

1) This paper proposed a power coupling system of the hydraulic hybrid city bus, and analyzed the operating modes of the system.

2) Kinetic analysis and kinematics analysis of the power coupler under hybrid driven mode were presented. The models of engine, hydraulic accumulator and hydraulic pump/motor were established, and the mathematical model of power coupler was built, based on Lagrange equation.

3) Simulation was proposed under Matlab/Simulink. The results show that the power coupling system proposed in this paper could solve the coupled problem of the hydraulic bus effectively. Compared with the traditional city bus, the low-powered engine can be taken into the hydraulic hybrid city bus to improve the fuel economy and emission performance. 


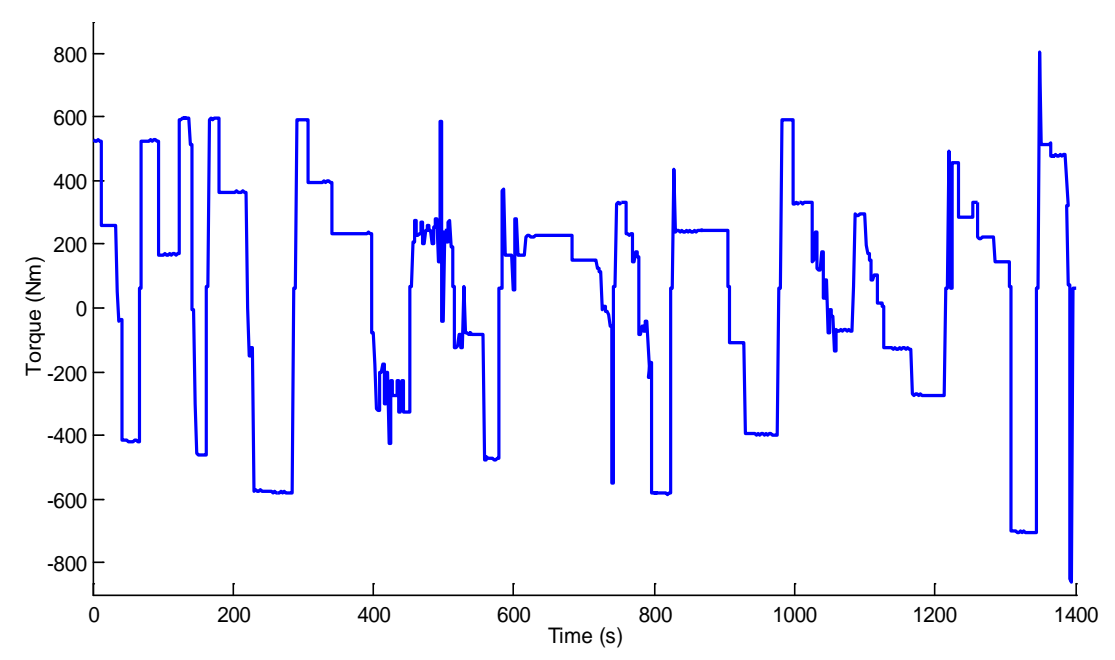

Figure 13. Vehicle demand torque curve.



Figure 14. Coupling torque characteristic curve.

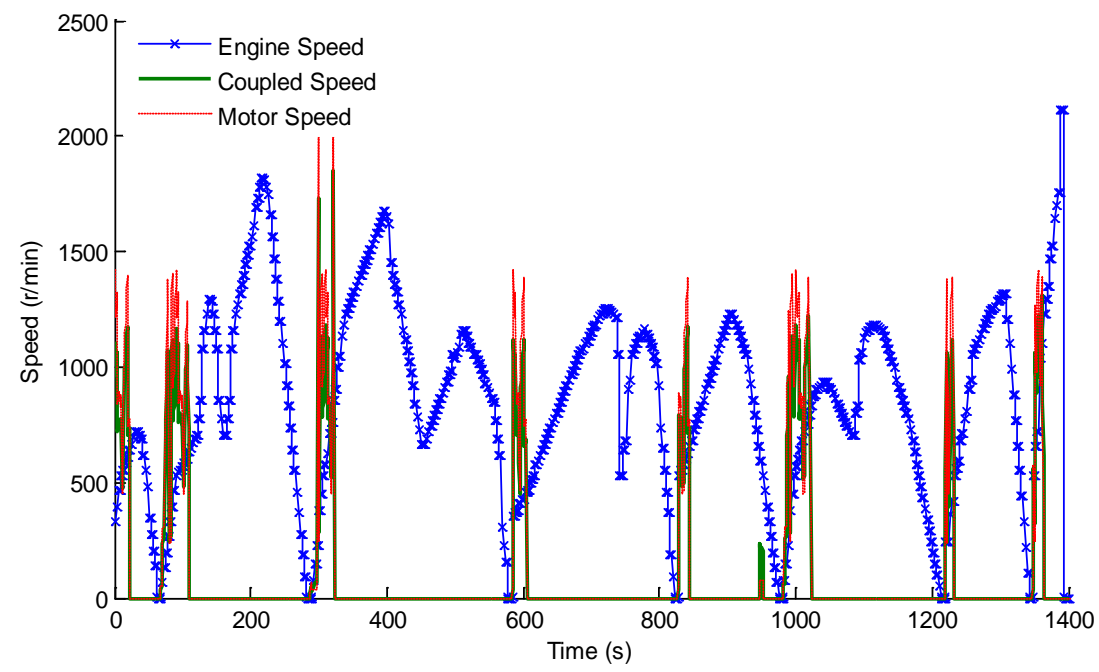

Figure 15. Speed coupling characteristic curve. 


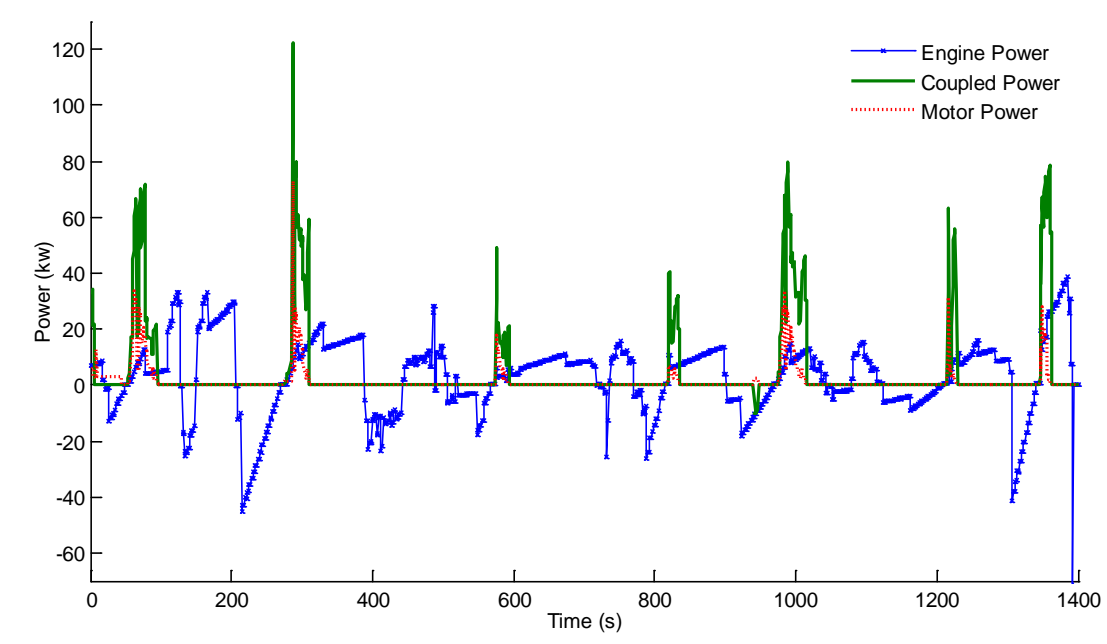

Figure 16. Power coupling characteristic curve.

\section{Acknowledgements}

This research is supported by the National Natural Science Foundation of China (Grant No. 51275280) and Shandong Province Science and Technology Development Program (Grant No. 2011GGX10505).

\section{References}

[1] Deppen, T.O., Stelson, K.A., Meyer, J.J. and Alleyne, A.G. (2012) Optimal Energy Use in a Light Weight Hydraulic Hybrid Passenger Vehicle. Journal of Dynamic Systems, Measurement, and Control, 134, 041009. http://dx.doi.org/10.1115/1.4006082

[2] Wojnarowski, J., Kopeć, J. and Zawiślak, S. (2006) Gears and Graphs. Journal of Theoretical and Applied Mechanics, 44, 139-162.

[3] Lang, S.Y. (2005) Graph-Theoretic Modeling of Epicyclic Gear Systems. Mechanism and Machine Theory, 10, 511529. http://dx.doi.org/10.1016/j.mechmachtheory.2004.12.001

[4] Wojnarowski, J. and Lidwin, A. (1975) The Application of Signal Flow Graphs—The Kinematic Analysis of Planetary Gear Trains. Mechanism and Machine Theory, 10, 17-31. http://dx.doi.org/10.1016/0094-114X(75)90054-3

[5] Benford, H.L. and Leising, M.B. (1981) The Lever Analogy: A New Tool in Transmission Analysis. SAE Technical Paper No. 810102.

[6] Tsai, L.W., Schultz, G. and Higuchi, N. (2001) A Novel Parallel Hybrid Transmission. Journal of Mechanical Design, 123, 161-168. http://dx.doi.org/10.1115/1.1365118

[7] Sun, H. (2010) Multi-Objective Optimization for Hydraulic Hybrid Vehicle Based on Adaptive Simulated Annealing Genetic Algorithm. Engineering Applications of Artificial Intelligence, 23, 27-33. http://dx.doi.org/10.1016/j.engappai.2009.09.005

[8] Qin, D.T., You, G.P. and Hu, J.J. (2009) Operation Mode Analysis and Parameters Design of a Novel Power Split Hybrid Transmission System. Chinese Journal of Mechanical Engineering, 45, 184-191. http://dx.doi.org/10.3901/JME.2009.02.184

[9] Wei, Y.Y., Lin, Y. and He, H.W. (2005) The Applied Research on Double Row Planetary Gear Train for HEV. Automobile Technology, 8, 11-14.

[10] Liu, T., Jiang, J.H., Sun, H. and Zhao, L.J. (2009) Research and Progress of the Hydrostatic Hybrid Vehicle. Automotive Engineering, 31, 586-591.

[11] Zhang, J., Luo, N.N. and Jiang, J.H. (2012) Research Survey of Hydraulic Hybrid Vehicles. Machine Tool \& Hydraulics, 6, 67-79.

[12] Peng, D., Yin, C.L. and Zhang, J.W. (2006) Advanced Braking Control System for Hybrid Electric Vehicle Using Fuzzy Control Logic. SAE Paper No. 2006-01-3583.

[13] Chen, H.Z. and Yuan, S.H. (2003) Design of the Hydraulic System for Braking Energy Storage to City Vehicle. Chinese Hydraulics \& Pneumatics, 4, 1-3.

[14] Yang, Y., Zhao, X.F., Qin, D.T., Duan, Z.H. and Gong, H. (2012) Design and Operation Mode Coupling Characteris- 
tics Analysis on the New Transmission System of Hybrid Electric Vehicle. Automotive Engineering, 34, 968-975.

[15] Yang, K.Z., Cheng, G.G. and Li, Z.S. (2009) Fundamentals of Machine Design. Higher Education Press, Beijing.

[16] Theoretical Mechanics Research Group of Harbin Institute of Technology (2009) Theoretical Mechanics. Higher Education Press, Beijing.

[17] Diao, Y.F., Wei, H.X. and Yang, E.X. (1999) The Application of Plane Unfolding Formula of Lagrange Equation in Mechanism Dynamics. Journal of Harbin Engineering University, 20, 91-96.

[18] Shan, M. (2009) Modeling and Control Strategy for Series Hydraulic Hybrid Vehicles. Doctoral Dissertation, University of Toledo, Toledo. 